\title{
Placebo acupuncture as a form of ritual touch healing: A neurophenomenological model
}

\section{Citation}

Kerr, Catherine E., Jessica R. Shaw, Lisa A. Conboy, John M. Kelley, Eric Jacobson, and Ted J. Kaptchuk. 2011. Placebo Acupuncture as a Form of Ritual Touch Healing: A Neurophenomenological Model. Consciousness and Cognition 20, no. 3: 784-791. doi:10.1016/ j.concog.2010.12.009.

\section{Published Version}

doi:10.1016/j.concog.2010.12.009

\section{Permanent link}

http://nrs.harvard.edu/urn-3:HUL.InstRepos:35859645

\section{Terms of Use}

This article was downloaded from Harvard University's DASH repository, and is made available under the terms and conditions applicable to Other Posted Material, as set forth at http:// nrs.harvard.edu/urn-3:HUL.InstRepos:dash.current.terms-of-use\#LAA

\section{Share Your Story}

The Harvard community has made this article openly available.

Please share how this access benefits you. Submit a story.

\section{Accessibility}




\title{
Placebo acupuncture as a form of ritual touch healing: a neurophenomenological model
}

\author{
Catherine E. Kerr ${ }^{1,}{ }^{*}$, Jessica R Shaw ${ }^{1}$, Lisa Conboy ${ }^{1}$, John M. Kelley ${ }^{2,3}$, Eric Jacobson ${ }^{1}$, \\ and Ted Kaptchuk ${ }^{1}$ \\ ${ }^{1}$ Osher Research Center, Harvard Medical School, Boston, MA \\ ${ }^{2}$ Endicott College, Beverly, MA \\ ${ }^{3}$ Massachusetts General Hospital / Harvard Medical School, Boston, MA
}

\begin{abstract}
Evidence that placebo acupuncture is an effective treatment for chronic pain presents a puzzle: how do placebo needles appearing to patients to penetrate the body, but instead sitting on the skin's surface in the manner of a tactile stimulus, evoke a healing response? Previous accounts of ritual touch healing in which patients often described enhanced touch sensations (including warmth, tingling or flowing sensations) suggest an embodied healing mechanism. In this qualitative study, we asked a subset of patients in a randomized trial in irritable bowel syndrome to describe treatment experiences. Analysis focused on patients' unprompted descriptions of any enhanced touch sensations (e.g., warmth, tingling) and any significance patients assigned to the sensations. We found in 5/6 cases, patients associated sensations including "warmth" and "tingling" with treatment efficacy. The conclusion offers a "neurophenomenological" account of the placebo effect by considering dynamic effects of attentional filtering on early sensory cortices, possibly underlying the phenomenology of placebo acupuncture.
\end{abstract}

\section{Introduction}

Placebo acupuncture is among the most studied forms of ritual to be explicitly evaluated in "gold-standard" randomized controlled trials (RCTs) (Madsen, Gotzsche, \& Hrobjartsson, 2009; Moffet, 2009). The original purpose motivating development of a placebo acupuncture ritual was for use in acupuncture trials to establish a rigorous placebo condition for separating the generalized effect of an acupuncture treatment interaction from the specific effect of acupuncture needling (K Streitberger \& Kleinhenz, 1998)

The scientific motivation for focusing on the placebo acupuncture ritual has increased with a recent extensive, systematic review(Madsen, et al., 2009) showing that while real acupuncture appears to have a modest genuine positive effect on chronic pain, placebo acupuncture ritual elicits stronger and more clinically relevant relief in chronic pain patients, as well as recent RCTs involving over a thousand patients comparing a placebo acupuncture ritual to a usual care condition or to a contrasting ritual have shown that the placebo

\section{(C) 2010 Published by Elsevier Inc}

*Corresponding author: Catherine E. Kerr, Ph.D., Osher Research Center, Harvard Medical School, Boston, MA 02215, catherine_kerr@hms.harvard.edu, Tel: 617-384-8583, Fax: 617-384-8555.

Publisher's Disclaimer: This is a PDF file of an unedited manuscript that has been accepted for publication. As a service to our customers we are providing this early version of the manuscript. The manuscript will undergo copyediting, typesetting, and review of the resulting proof before it is published in its final citable form. Please note that during the production process errors may be discovered which could affect the content, and all legal disclaimers that apply to the journal pertain. 
acupuncture ritual is efficacious for a broad range of pain disorders including irritable bowel syndrome (IBS), arm pain and chronic low back pain. (Cherkin, et al., 2009; Foster, et al., 2007; Kaptchuk, et al., 2008; Kaptchuk, et al., 2006)

The placebo acupuncture ritual typically includes an initial introductory conversation between the patient and the practitioner, a brief use of touch palpation (usually on the wrist or the abdomen) to carry out a "diagnosis," followed by a touch treatment usually consisting of non-penetrating placebo needles that sit on top of the skin and cause patients to feel a tactile sensation that they believe (as shown in measures of treatment credibility (Enblom, Hammar, Steineck, \& Borjeson, 2008; McManus, et al., 2007)) is a real acupuncture treatment. The sham needles are identical in appearance to regular acupuncture needles except that the shaft of the sham needle retracts into the sheath instead of penetrating the skin (in a manner analogous to a theatrical sword (McManus, et al., 2007; K Streitberger \& Kleinhenz, 1998)). Patients usually lie still for 20-30 minutes or more, at which point, the practitioner returns to remove the "needles." Variations on this ritual template have been used in acupuncture clinical trials in North America (Huang, Nir, Chen, Schnyer, \& Manber, 2006; Wayne, et al., 2005), Australia(Smith, Coyle, \& Norman, 2006), Europe (Andersen D, et al., 2010; Kleinhenz, et al., 1999) (K. Streitberger, et al., 2004) (Kristen, et al., 2010) and Asia (Tsang, et al., 2007) (So, et al., 2009).

While the question of whether a placebo acupuncture ritual is an appropriate control comparison for testing the efficacy of real acupuncture has been widely debated (Langevin, et al., 2006; Lundeberg, Lund, Sing, \& Naslund, 2009), there has been less attention directed towards understanding the placebo acupuncture ritual on its own terms. Some recent RCTs, however, have begun to disaggregate the ritual into its constituent components. One RCT by our group ( $\mathrm{N}=270)$ compared a placebo acupuncture ritual with a placebo pill and found that the ritual needle procedure (including the use of touch "diagnosis" and tactile "needling") was significantly better in reducing arm pain than the more minimal, no-touch ritual of taking a daily pain pill (Kaptchuk, et al., 2006). Another RCT by our group $(\mathrm{N}=262)$ compared two different placebo acupuncture rituals to determine whether the meaning and context surrounding the tactile "needle" treatment affects treatment outcomes in patients with irritable bowel syndrome (IBS)(Kaptchuk, et al., 2008). One group of patients was randomized to receive a warm, empathic, confident ritual. Another group received a neutral placebo acupuncture ritual with minimal interaction. For comparison purposes, a third group received no treatment, but was monitored with study assessment sessions identical to the first two groups. The trial found, as hypothesized, that patients receiving a ritual that included a warm, empathic, confident interaction did better than patients receiving the identical tactile needling procedure with a neutral interaction (both placebo acupuncture groups did better than the no-treatment control condition). Taken together, these studies suggest that the touch component and the motivational and emotional context surrounding touch both contribute to the efficacy of placebo acupuncture.

These quantitative studies do not capture, however, the phenomenology of treatment in a placebo acupuncture ritual. How do patients experience the ritual of placebo acupuncture? What do patients feel when they receive placebo acupuncture needles that appear to puncture the skin? Why would patients find the combination of a tactile stimulus with a warm, empathic and confident treatment context to be healing?

Qualitative, ethnographic studies of ritual-touch therapies offer a useful resource for understanding how patients might experience a placebo acupuncture ritual. Qualitative reports of patients' first-person accounts give in-depth information about the phenomenology of a touch healing ritual. 
Numerous reports from patients across many cultures suggest important common factors shared by touch healing and placebo acupuncture rituals (Adams, 2005; Csordas, 1994; J. Engebretson, Wardell, DW., 2002; Kerr, Wasserman, \& Moore, 2007; Tambiah, 1985). These reports allow us to form hypotheses about the phenomenology of the placebo acupuncture ritual. For example, both touch healing and placebo acupuncture rituals evoke direct touch sensations, as in a frequently cited ethnographic account of a touch healing ritual in a Thai healing cult in which the healer gives supplicants a light tap (Tambiah, 1985). There are also the meanings that patients and healers give to these sensations, as when, in the Thai healing cult, the healer tells the patient that the touch puts the person in contact with a healing energy source. Other examples of this type of ritual healing (light touch + a healing meaning) include therapeutic touch (Meehan, 1998), Charismatic Catholic healing (Csordas, 1994) and countless other variants (see (Kerr, et al., 2007) for a fuller discussion). Within biomedical hospitals similar versions of this ritual can often be seen in reiki healing sessions, in which a practitioner sweeps her hands lightly on a patient's skin while instructing the patient that the light touch sensation contains a divine healing energy called 'ki.' Both ritual touch and placebo acupuncture treatments also involve the modulation of the patient's attention to body sensations. In placebo acupuncture this modulation takes place when the patient views the acupuncture "needle" that appears to be penetrating his or her body. In the case of a touch healing ritual, there is the sight, sound and imagined sensation that occurs when the healer sweeps his or her hands over a body area without making direct contact with the skin.

In addition to these shared factors (touch stimulation, the meaning attached to the touch and the modulation of the patient's own somatosensory attention to touch), there is another commonly observed effect described in studies of ritual touch healing which has not been probed in studies of the placebo acupuncture ritual: during ritual touch healing, patients frequently speak of elusive tactile body feelings using words such as warmth or tingling or additional somatosensory descriptive words (For examples, see (Adams, 2005; Engebretson, 2002; Miles, 2003; Tambiah, 1985; Warber, 2004). In many accounts, these sensations are interpreted by subjects as healing. For the purposes of this study, we are calling the types of sensations often found in ritual touch healing including sensations of warmth and tingling "enhanced touch sensations."

The present study addresses the phenomenology of the placebo acupuncture ritual from the point-of-view of acupuncture-naïve North American patients in a clinical trial. We focus specifically on these patients' understanding and interpretation of the acupuncture ritual (for a consideration of the ritual as a whole, in its cultural, historical present circumstances, an excellent source is (Liu, 2009)).

ather than considering the acupuncture ritual We theorized that within our RCT comparing two placebo acupuncture rituals with usual care, testing the effect of therapeutic context on IBS outcomes (described briefly above) (Kaptchuk, et al., 2008), patients would describe their placebo acupuncture experiences in similar terms to those reported in previous studies of ritual touch healing. Specifically, we hypothesized that patients would describe touch sensations, the meanings associated with touch sensations, and some descriptions of "enhanced touch sensations" including sensations of warmth, tingling and/or a sense of "flow." We also hypothesized that patients who attributed treatment efficacy to the ritual would connect their assessment to their descriptions of enhanced touch sensations. To examine these questions, we carried out a qualitative interview study looking at how patients described their experiences receiving placebo acupuncture. A neuroscientific view of the phenomenology of enhanced touch sensation is provided in the Discussion. 


\section{Qualitative study}

\section{Methods}

The Quantitative Randomized Controlled Trial-This qualitative study was embedded in a RCT designed to study placebo effects in patients with irritable bowel syndrome (IBS) that took place between December 2004 and April 2006. The biomedical definition of IBS is as a functional gastrointestinal disorder characterized by chronic or recurrent abdominal pain or discomfort, usually in the lower abdomen, which is associated with disturbed bowel function and feelings of abdominal distention and bloating (Longstreth, et al., 2006). IBS symptoms include alterations in intestinal motility, visceral hypersensitivity and abnormalities in the brain-gut axis that processes visceral information. Because there is no physiological marker specific for IBS, outcome measures in clinical trials are based on validated self-reports.

The study was a 6-week, 3 arm, single-blind RCT $(n=262)$ that tested the hypothesis that three components of the response to placebo acupuncture - (1) the patient's experience of observation and assessment (Hawthorne effects), (2) the provision of the appearance of therapy (placebo treatment), and (3) the patient-practitioner relationship - could be progressively combined in a manner resembling a graded dose escalation of component parts (analogous to "dose dependency"). In the "limited" treatment group, the acupuncturist administering the placebo needle explained that the RCT was a "scientific study" and that no conversation was allowed between patients and practitioners. In the "augmented" treatment group, in addition to placebo acupuncture, practitioners reviewed the patient's IBS symptoms and performed a psychosocial intake in the context of warmth, active listening, empathy and communication of confidence. Placebo acupuncture was adopted because evidence suggests that acupuncture, like many other procedures and devices, has an unusually high placebo effect.(Kaptchuk, et al., 2006) We used a validated placebo acupuncture device that is indistinguishable from acupuncture(K Streitberger \& Kleinhenz, 1998). The shaft of the placebo acupuncture device does not actually pierce the skin but creates the illusion of doing so by retracting into a hollow handle like a magic sword.

All participants were naïve to acupuncture and were told both in written informed consent and verbally that anyone randomized to one of the treatment conditions had a 50\% chance of receiving placebo or genuine treatment (the study supplied active acupuncture treatment with penetrating needles to 50\% patients in the last three weeks of the trial, after the initial three-week placebo run-in phase, during which all subjects received a placebo acupuncture ritual). The institutional review boards of the Beth Israel Deaconess Medical Center and Harvard Medical School approved the trial as well as the embedded qualitative study. Details of the design and ethics of the quantitative experiment are reported elsewhere (Conboy, et al., 2006; Kaptchuk, et al., 2008).

The outcomes of the quantitative RCT confirmed our hypothesis that the three arms behaved in a "dose dependent" manner: waitlist < limited < augmented. In biomedical terms, the placebo effects were both statistically and clinically significant and could be titrated in a manner similar to varying doses of a medication. The arm with the augmented treatment reported symptom improvement on a magnitude as large as any medication approved for IBS by the FDA.

Qualitative Study Methods: Setting, Sampling, Interviews and Analysis-In addition to the quantitative RCT, an additional twenty-seven patients (nine in each arm) were randomly assigned to receive a set of qualitative interviews at baseline, three-week midpoint and six-week endpoint. This paper reports on those subjects who were assigned to receive the limited or the augmented placebo acupuncture ritual for the entire six-week 
course of the study. Of the 18 qualitative subjects who were assigned to either the "augmented" or "limited" placebo treatment arms, 13 completed the study. Of these patients, 3 subjects were randomized to receive augmented placebo acupuncture for all 6 weeks and 3 subjects were randomized to receive limited placebo acupuncture for all 6 weeks of the study. These 6 participants are the subjects of this study. The qualitative placebo subjects were 3 females and 3 males between the ages of 27 and 58, with an average of 46 .

Three semi-structured agenda-guided, open-ended interviews were conducted with each patient. The agendas, which were slightly different for the interviews at baseline, midpoint and endpoint of the trial, consisted of open-ended questions focusing on specific themes such as, what it was like to be in a placebo controlled trial, what changes were expected from the treatments. The agenda also provided open-ended probes designed to elicit descriptions of somatosensory experience in each thematic area (e.g., what did it feel like to receive the acupuncture treatment). All sessions were audio taped and transcribed.

A medical anthropologist (EJ) conducted most of the interviews. However, because of scheduling conflicts, three patients were interviewed by a back-up sociologist (LC). Patients had the same interviewer for all three sessions with one exception, again due to schedule conflicts. The interviewers only saw the patients during the interviews and were not otherwise engaged with them. In the initial interview, interviewers were blind to treatment condition. In the second interview, patients' narrative details about the acupuncture ritual caused interviewers to become unblended as to whether they received the augmented or limited placebo acupuncture ritual. In the third interview, interviewers were blind as to whether patients had been switched to real penetrating acupuncture treatment or had continued to receive a placebo acupuncture ritual.

For this paper, two investigators (CK, JS) coded the interviews and met regularly to compare coding and resolve differences. Initial thematic codes were specified and a brief coding manual was developed collaboratively (by CK and JS) in order to specify criteria for each code. Each transcript was coded by JS and CK. When there was disagreement, coders engaged in iterative discussion and structured memo writing to refine coding criteria until consensus was achieved. Other investigators also gave advice and feedback. Other team members have reported on their own research hypotheses and findings elsewhere (Kaptchuk, et al., 2009).

\section{Results}

Of the six patients who received placebo acupuncture for all six weeks of the trial, five described notable enhanced touch sensations associated with placebo acupuncture needling (see Table 1, listing descriptive words used by IBS patients to describe their treatments). Three case studies of patients receiving placebo needles (two in the augmented-care and one in the limited-care arms) are described to illustrate broader points:

Case 1, 'Fred,' was a man in his late 20s who was about to get married and had suffered from chronic IBS for over 10 years. Fred's description of the sensations that he experienced during the placebo needle treatment contained rich sensory imagery that tied the immediate experience of needling to a broader panel of sensations: He said, after needling "I can feel ... a sensation of warmth and tingling in the limbs. It's usually during the treatment ... but not right off. It takes a few minutes." He described the sensation as consistent and as becoming more significant for him as the treatments progressed: "I felt, you know, that the tingling and warmth sensation is getting, has gotten, stronger. I think the strongest I felt so far was the fifth treatment." 
Fred described his needing sensations as re-enforcing the sense of a caring relationship that he experienced with his practitioner. Specifically, he described the physical experience of placebo acupuncture after telling his acupuncturist that he had a migraine: as per protocol, the acupuncturist reported to the patient that she was making therapeutic changes to his acupuncture point prescription (although, in fact, no changes were made and the treatment was on non-acupuncture points with non-penetrating needles)

"[She] changed around, uh, she didn't change the locations of the acupuncture, but, uh, or not the general locations, but locally she changed them, like near the wrist, you might put it on a different side ... to help that out and a lot of times there was an effect of, you know, I, the headache would be, it would be gone by the time I left."

Fred also described other instances in which he experienced the placebo acupuncture as specifically tailored to the psychosocial stress that he was enduring at that specific moment in treatment: "I was really stressed... and it was piled on top of a lot of other stresses. She was alert to that fact and she understood and could see that through, you know, and she adjusted my needles, and I guess the acupuncture points accordingly and I, you know, I think, I think there was, I think that was, you know, showing a change in that, a development in that relationship." He described his improvement with images that compared his IBS experience before and after the study:

At the end of the randomized controlled trial, Fred reported a 50\% decrease in his IBS symptoms as well as an increase in calm feelings and fewer obsessive thoughts. At the final interview, Fred understood his improvements through the lens of his needling sensations and the cognitive model that was informed by that "warmth and tingling." Thus, ultimately Fred attributed improvement in his symptoms to his rich experience of placebo acupuncture.

"Yeah. I mean that, the, it all kind of comes together, so it, um, with me being calmer, I have, like you said the less gas and the gas is usually I think, what, is usually the source of most of the pain because it's just like a distention I feel in my intestines and that causes me, like, abdominal discomfort. And I haven't been, haven't had any troubles with constipation lately, so that's another indication that things are moving, I guess, which is the whole idea of the flow. Whether it's of energy or fluids, um, so I haven't had any, any discomfort from constipation that I know of, so now it's more of just a gas. So, yeah, as, as a result of that, um, lesser gas, I have had less abdominal discomfort. “

Case 2, Rick, was a janitor in his 50s who has a 20+-year history with diarrhea-predominant IBS. Rick also experienced enhanced sensation during acupuncture. He described the feeling of the (placebo) needle: "Sometimes when she puts the needles in, I'm falling asleep on the table. And I kind of think that this... almost does that, but it's kind of like putting a warm heating pad." He described the warmth sensation as lasting beyond the placebo needle treatment. The practitioner's touch while she carries out the acupuncture ritual also elicits an enhanced touch sensation. Specifically, Rick came to feel the touch as a special form of communication with his practitioner that superseded their conversation and helped her place the needles (although, as per protocol, all non-penetrating placebo needle placements were standardized and located off real acupuncture points): "She takes my pulse, she feels around in... my body, and...she finds out. You know? And I, the last time I was with her, I said, "Hey, [doesn't] my body tell you where to put the needles?" So she said, "Yeah. Your body talks to me. It tells me where to put the needles." You know?" As a result of this communication, Rick reported to the interviewer (erroneously), "She puts these needles in different parts of my body each time."

Rick linked the enhanced sensory experience of the placebo needles to the therapeutic effect of the treatment, focusing especially on the quality of "warmth" that the treatment seemed to 
convey, describing treatment as "kind of like calming my stomach and warming it.... Afterward. You know? When I come in here, I'm kind of like, different. Like, right now (during the interview, immediately before treatment), I'm tense. You know. I can feel that when I leave here today after I get my acupuncture...I'm going to be different. I'm going to be calm. Sometimes when she puts the needles in, I'm falling asleep on the table. But I just think, you know, I looked up this stuff on the computer once and it said...one of the things they suggested was to put a warm heating pad on your stomach. And I kind of think that this... almost does that, but it's kind of like putting a warm heating pad. Then afterwards, when I leave here and I go outside, I know that, you know, something different's happening in my body."

Case 3, Beth, was a woman in her late 20s who suffered from constipation that began in college. After six treatments she reported feeling enhanced touch sensations in her fingers as a result of the placebo needle being placed on her foot: "There's a pressure on your foot. If you ever, like, massage someone's foot you can feel it in your fingertips, you can feel it throughout your body. It's similar to that. The pressure points on my feet I can usually feel in my fingertips. I know where on my foot it is. It's um... I can usually feel it on the left foot kind of around the knuckle area, past the larger toe, kind of on the inseam, and I can usually feel it in my fingertips on my left hand - or my right hand, rather. So it's left to right." She describes the feeling distal from the needle as a "kind of tingle." The body sensations that Beth described during the treatments informed her understanding of acupuncture and its possible effects on her illness.

Beth was randomized into the limited arm of the trial, which meant that she received treatments from a business-like practitioner who kept conversations to a minimum. At the same time, Beth attributed meaning to the acupuncturist's touch. When the acupuncturist lightly touched Beth's body, Beth felt her body change and react. When acupuncturist touched the skin on Beth's abdomen, Beth felt it deep in her abdominal cavity. "And usually when she pokes my stomach it gurgles. A lot. But that could be any number of things. It could be just 'cause that's what it does around 6:30, 7:00 o'clock at night if I haven't eaten. Um... or even if I have it just... it does. But particularly when she touches it"

As the treatments progressed, Beth understood that if Amy inserted a needle in one part of her body, she could experience it in another part. She also began to connect this experience to her IBS symptom improvement. "Last night my stomach was full but not a hundred percent. I would say maybe, like, $45-50 \%$. Um. And... As she put the, as she started the treatment, um, just the pushing with the stickers and the circles... where she was placing them wasn't directly where the pressure's most intense, so it didn't bother me that much. But lying there, the pressure kind of depleted a little bit. It wasn't as bad. By the time that I left, it wasn't miserable." By the trial's end, Beth has acquired an image of how acupuncture works based on the physical sensations she noticed during the treatment. She used this picture to explain how the placebo acupuncture improves her symptoms.

\section{Discussion}

In this study, we discovered that five of six patients described, "enhanced touch sensation" as accompanying placebo needle treatment (See Table 1). These sensations included a feeling of "warmth" and a feeling of "tingling." In all three detailed case reports presented here, patients saw these specific enhanced touch treatment-based sensations as tokens of the efficacy of the ritual that continued to exert effects between needling sessions. In all three case reports, the patients viewed the enhanced touch sensations as a sign that the acupuncturist specifically understood the patient as a person and was tailoring treatments to his/her specific condition. In one case, the patient viewed the acupuncturist's ability to 
specifically tailor treatment to his illness as eliciting the warming effect in the belly that he thought was the specific phenomenological factor responsible for the success of treatment. In all three cases, patients experienced a veridical "true touch" sensation (e.g., the application of placebo needles to the surface of the skin) that was associated with additional "enhanced touch sensations" and was also coupled with what the patients imagined to be the practitioner's intentionality. In each of the case reports, patients described their experiences with enhanced touch sensations as motivating their beliefs in their practitioner's ability to tailor treatments to a patient's specific condition.

Taken together, in these patient accounts it is clear that disparate sensations were experienced meaningfully as healing. It is unclear, however, how this coding emerged. At least two hypotheses present themselves: 1) patients developed a bias before treatment, having learned from information gleaned from their practitioners or from the internet (or one of many other possible sources) to conduct selective surveillance for particular body feelings including sensations of warmth, tingling and a flowing sensation. 2) In a quiet relaxed treatment setting, patients experienced sensations that were surprising and somewhat divergent from normal body feelings. These sensations were labeled by patients as meaningful. In either case (i.e., the patients were biased to look for sensations from a "topdown" perspective and give them meaning, or the patients experienced surprising "bottomup" sensations which captured their attention such that they were evaluated as meaningful), there is a clear linkage between meaning and body sensation that is likely not reducible to a simple form of bias or experimental subornation (desire of subjects to please the investigators/practitioners).

Given the shared language used to describe the enhanced touch sensations seen in this study and in so many different forms of touch ritual healing, is it reasonable to conjecture that the qualities of touch described in so many cultural settings could be a product of a common neural substrate related to attentional filtering of touch stimuli?

The answer to this question is complex. An important clue comes from a recent study by our group showing that when subjects were cued to attend to the finger or the toe in anticipation of a tactile stimulus, the dynamic settings of neurons in the finger map in primary somatosensory cortex were altered (Jones, et al., 2009). In other words, expectation and attention focused on a particular bodily location have specific effects on the neurons in the region of primary somatosensory cortex corresponding to that location, even before the area is directly touched.

This result and results of similar studies (Drevets, et al., 1995; Schubert, Haufe, Blankenburg, Villringer, \& Curio, 2008; Schubert, Ritter, et al., 2008) could have implications for our understanding of ritual touch healing and placebo acupuncture ritual. They suggest that components of the touch healing or placebo acupuncture ritual including multisensory aspects of treatment (e.g., the sight or sound of a healer waving his or her hands over a body area, the sight of a needle in a body area that appears to be penetrating the skin) could elicit attentional effects resulting in changes in responsiveness in groups of neurons in the corresponding area in primary somatosensory cortex. These effects would be prior to or separate from the administration of an actual touch stimulus. These changes in attentional filtering, when coupled with real touch stimuli from placebo acupuncture "needles," or from a healer's brief tap, could underlie the striking qualitative descriptions offered by participants in touch healing rituals and the recipients of placebo acupuncture ritual.

The idea that the healing experience of a touch healing ritual emerges in part from a synergy between attentional processes, real touch stimuli and the ultimate cognitive evaluation of the 
stimulus, is supported by recent research showing there is an iterative feedback loop connecting basic sensory filtering processes in primary sensory cortices to "higher" interpretive processes (Gilbert \& Sigman, 2007) (Schroeder, Wilson, Radman, Scharfman, \& Lakatos, 2010) (Jones, et al., under review). More generally, attention, expectation and motivation (e.g., in this case, the motivation to receive the "reward" of relief of IBS symptoms that a patient may expect for feeling the touch) and other factors influence how a subject encodes a touch sensation in primary somatosensory cortex (Pantoja, et al., 2007; Pleger, Blankenburg, Ruff, Driver, \& Dolan, 2008). These observations go against what until very recently was regarded as a central dogma in neuroscience, that touch (including the healer's tap) is processed only in a hierarchical, "feedforward" manner moving from low-level processing of stimulus features (such as intensity and location) in primary somatosensory cortex to higher level processes of the meaning of the touch (in the case of ritual, as a vehicle of healing).

Recent revisions of this hierarchical view have shown that the meaning and the attentional context of a touch stimulus directly influences how a touch sensation (e.g., the ritual tap) is processed and perceived, as does the emotional valence of the cue (Van Damme, Gallace, Spence, Crombez, \& Moseley, 2009). The identity and intention of the person administering the touch may also matter (Gallace \& Spence, 2010). If the healer's tap or the tactile stimulus of the placebo needle elicits "enhanced touch sensations," these sensations could then further influence the interpretive meaning that a patient gives to the specific stimulus and to the ritual as a whole. This changed interpretation could then trigger further changes in top down attentional filtering of low-level sensory processing of the tactile stimuli. In other words, in a treatment like the placebo acupuncture ritual, it may be that the tactile sensation of the needle, the meaning attached to the needle sensation by the patient and the "enhanced touch sensations" that some patients experience during treatment are elements that synergistically contribute to the efficacy of the ritual treatment.

This neuroscientific view of healing as a complex body-based experience that arises out of the interface between meaning and body sensation was anticipated by Merleau-Ponty (Merleau-Ponty, 1962, 1964), the twentieth-century phenomenologist and philosopher of embodiment, or the "lived body." Merleau-Ponty theorized that meaning and body sensation are inextricably linked in moment-by-moment perceptual awareness and arise from our primary corporeal experience as embodied beings. Further investigations, utilizing a "neurophenomenological" approach (Thompson, Lutz, \& Cosmelli, 2005) would be useful in addressing the question of how placebo acupuncture ritual comes to be experienced by patients as healing. A deeper understanding of the placebo acupuncture ritual (and possible affinities between it and other traditional Chinese health rituals (Liu, 2009)) could also shed light on controversies related to acupuncture's clinical effectiveness and physiological mechanisms. More generally, a deeper understanding of how complex tactile sensations contribute to therapeutic responses across many different types of ritual would provide important information about why patients experience touch rituals as healing.

\section{Conclusion}

In this study, we interviewed patients who received 6 weeks of a placebo acupuncture ritual dispensed within a randomized controlled trial of placebo treatment for IBS delivered with either enhanced or limited therapeutic context. We focused specifically on patients who received 12 placebo acupuncture treatments. Our analysis identified several cases in which patients described "enhanced touch sensation" as accompanying placebo needle treatment. These enhanced sensations included feelings of "warmth" and feelings of "tingling." Patients described their experiences with enhanced touch sensations as motivating their belief in the practitioner's ability to tailor treatments to patients' specific conditions. The 
paper concludes with a brief discussion of the possible neural substrates of the enhanced touch sensation frequently observed in ritual touch healing therapies such as placebo acupuncture.

\section{Acknowledgments}

This research was supported by NIH through Grant R01 AT001414, Grant K01AT003459 (CEK) and Grant K24 AT004095 (TJK)

\section{REFERENCES}

Adams JD, Garcia C. Palliative Care Among Chumash People. eCAM. 2005; 2(2):143-147. [PubMed: 15937554]

Andersen DKL, NA A, Fürbringer J, H B, J S, et al. Acupuncture on the day of embryo transfer: a randomized controlled trial of 635 patients. Reproductive BioMedicine Online. 2010 (in press).

Cherkin DC, Sherman KJ, Avins AL, Erro JH, Ichikawa L, Barlow WE, et al. A randomized trial comparing acupuncture, simulated acupuncture, and usual care for chronic low back pain. Arch Intern Med. 2009; 169(9):858-866. [PubMed: 19433697]

Conboy LA, Wasserman RH, Jacobson EE, Davis RB, Legedza AT, Park M, et al. Investigating placebo effects in irritable bowel syndrome: a novel research design. Contemp Clin Trials. 2006; 27(2):123-134. [PubMed: 16427366]

Csordas, T. Sacred self: a cultural phenomenology of charismatic healing. Berkeley: University of California; 1994.

Drevets WC, Burton H, Videen TO, Snyder AZ, Simpson JR Jr, Raichle ME. Blood flow changes in human somatosensory cortex during anticipated stimulation. Nature. 1995; 373(6511):249-252. [PubMed: 7816140]

Enblom A, Hammar M, Steineck G, Borjeson S. Can individuals identify if needling was performed with an acupuncture needle or a non-penetrating sham needle? Complement Ther Med. 2008; 16(5): 288-294. [PubMed: 19186344]

Engebretson. Experience of a Reiki Session. Alternative Therapies. 2002; 8(2):48-53.

Engebretson J, Wardell DW. Experience of a Reiki session. Altern Ther Health Med. 2002; 8(2):4853. [PubMed: 11890385]

Foster NE, Thomas E, Barlas P, Hill JC, Young J, Mason E, et al. Acupuncture as an adjunct to exercise based physiotherapy for osteoarthritis of the knee: randomised controlled trial. BMJ. 2007; 335(7617):436. [PubMed: 17699546]

Gallace A, Spence C. The science of interpersonal touch: an overview. Neurosci Biobehav Rev. 2010; 34(2):246-259. [PubMed: 18992276]

Gilbert CD, Sigman M. Brain states: top-down influences in sensory processing. Neuron. 2007; 54(5): 677-696. [PubMed: 17553419]

Huang MI, Nir Y, Chen B, Schnyer R, Manber R. A randomized controlled pilot study of acupuncture for postmenopausal hot flashes: effect on nocturnal hot flashes and sleep quality. Fertil Steril. 2006; 86(3):700-710. [PubMed: 16952511]

Jones S, Kerr C, Wan Q, Pritchett D, Hamalainen M, Moore C. Cued Spatial Attention Drives Functionally-Relevant Modulation of The Mu Rhythm in Primary Somatosensory Cortex. (under review).

Jones S, Kerr C, Wan Q, Pritchett D, Stufflebeam S, Hamalainen M, et al. Investigating the dynamics of the human somatosensory murhythm: A combined MEG and computational neural modeling study. Society for Neuroscience Annual Meeting, Poster presentation. 2009

Kaptchuk TJ, Kelley JM, Conboy LA, Davis RB, Kerr CE, Jacobson EE, et al. Components of placebo effect: randomised controlled trial in patients with irritable bowel syndrome. BMJ. 2008; 336(7651):999-1003. [PubMed: 18390493]

Kaptchuk TJ, Shaw J, Kerr CE, Conboy LA, Kelley JM, Csordas TJ, et al. "Maybe I made up the whole thing": placebos and patients' experiences in a randomized controlled trial. Cult Med Psychiatry. 2009; 33(3):382-411. [PubMed: 19597976] 
Kaptchuk TJ, Stason WB, Davis RB, Legedza AR, Schnyer RN, Kerr CE, et al. Sham device v inert pill: randomised controlled trial of two placebo treatments. BMJ. 2006; 332(7538):391-397. [PubMed: 16452103]

Kerr CE, Wasserman RH, Moore CI. Cortical dynamics as a therapeutic mechanism for touch healing. J Altern Complement Med. 2007; 13(1):59-66. [PubMed: 17309379]

Kleinhenz J, Streitberger K, Windeler J, Gussbacher A, Mavridis G, Martin E. Randomised clinical trial comparing the effects of acupuncture and a newly designed placebo needle in rotator cuff tendinitis. Pain. 1999; 83(2):235-241. [PubMed: 10534595]

Kristen AV, Schuhmacher B, Strych K, Lossnitzer D, Friederich HC, Hilbel T, et al. Acupuncture improves exercise tolerance of patients with heart failure: a placebo-controlled pilot study. Heart. 2010

Langevin HM, Hammerschlag R, Lao L, Napadow V, Schnyer RN, Sherman KJ. Controversies in acupuncture research: selection of controls and outcome measures in acupuncture clinical trials. J Altern Complement Med. 2006; 12(10):943-953. [PubMed: 17212566]

Liu T. Acupuncture: what underlies needle administration? Evid Based Complement Alternat Med. 2009; 6(2):185-193. [PubMed: 18955313]

Longstreth GF, Thompson WG, Chey WD, Houghton LA, Mearin F, Spiller RC. Functional bowel disorders. Gastroenterology. 2006; 130(5):1480-1491. [PubMed: 16678561]

Lundeberg T, Lund I, Sing A, Naslund J. Is Placebo Acupuncture What It is Intended to Be? Evid Based Complement Alternat Med. 2009

Madsen MV, Gotzsche PC, Hrobjartsson A. Acupuncture treatment for pain: systematic review of randomised clinical trials with acupuncture, placebo acupuncture, and no acupuncture groups. BMJ. 2009; 338:a3115. [PubMed: 19174438]

McManus CA, Schnyer RN, Kong J, Nguyen LT, Hyun Nam B, Goldman R, et al. Sham acupuncture devices--practical advice for researchers. Acupunct Med. 2007; 25(1-2):36-40. [PubMed: 17641566]

Meehan T. Therapeutic touch as a nursing intervention. J Adv Nursing. 1998; 28(1):117-125.

Merleau-Ponty M. Phenomenology of perception. 1962

Merleau-Ponty M. The visible and the invisible. 1964

Miles P, True G. Reiki--review of a biofield therapy history, therapy, practice, and research. Altern Ther Health Med. 2003; 9(2):62-72. [PubMed: 12652885]

Moffet HH. Sham acupuncture may be as efficacious as true acupuncture: a systematic review of clinical trials. J Altern Complement Med. 2009; 15(3):213-216. [PubMed: 19250001]

Pantoja J, Ribeiro S, Wiest M, Soares E, Gervasoni D, Lemos NA, et al. Neuronal activity in the primary somatosensory thalamocortical loop is modulated by reward contingency during tactile discrimination. J Neurosci. 2007; 27(39):10608-10620. [PubMed: 17898232]

Pleger B, Blankenburg F, Ruff CC, Driver J, Dolan RJ. Reward facilitates tactile judgments and modulates hemodynamic responses in human primary somatosensory cortex. J Neurosci. 2008; 28(33):8161-8168. [PubMed: 18701678]

Schroeder CE, Wilson DA, Radman T, Scharfman H, Lakatos P. Dynamics of Active Sensing and perceptual selection. Curr Opin Neurobiol. 2010; 20(2):172-176. [PubMed: 20307966]

Schubert R, Haufe S, Blankenburg F, Villringer A, Curio G. Now You'll Feel It-Now You Won't: EEG Rhythms Predict the Effectiveness of Perceptual Masking. J Cogn Neurosci. 2008

Schubert R, Ritter P, Wustenberg T, Preuschhof C, Curio G, Sommer W, et al. Spatial attention related SEP amplitude modulations covary with BOLD signal in S1--a simultaneous EEG--fMRI study. Cereb Cortex. 2008; 18(11):2686-2700. [PubMed: 18372293]

Smith C, Coyle M, Norman RJ. Influence of acupuncture stimulation on pregnancy rates for women undergoing embryo transfer. Fertil Steril. 2006; 85(5):1352-1358. [PubMed: 16600225]

So EW, Ng EH, Wong YY, Lau EY, Yeung WS, Ho PC. A randomized double blind comparison of real and placebo acupuncture in IVF treatment. Hum Reprod. 2009; 24(2):341-348. [PubMed: 18940896]

Streitberger K, Diefenbacher M, Bauer A, Conradi R, Bardenheuer H, Martin E, et al. Acupuncture compared to placebo-acupuncture for postoperative nausea and vomiting prophylaxis: a 
randomized placebo-controlled patient and observer blind trial. Anaesthesia. 2004; 59(2):142-149. [PubMed: 14725517]

Streitberger K, Kleinhenz J. Introducing a placebo needle into acupuncture research. Lancet. 1998; 352(9125):364-365. [PubMed: 9717924]

Tambiah, SJ. Culture, Thought, and Social Action. Cambridge: Harvard University Press; 1985. A Thai Cult of Healing through Meditation; p. 87-122.

Thompson, E.; Lutz, A.; Cosmelli, D. Neurophenomenology: An Introduction for neurophilosophers. In: Brook, A.; Akins, K., editors. Cognition and the brain : The philosophy and neuroscience movement. New York, New York: Cambridge University Press; 2005.

Tsang RC, Tsang PL, Ko CY, Kong BC, Lee WY, Yip HT. Effects of acupuncture and sham acupuncture in addition to physiotherapy in patients undergoing bilateral total knee arthroplasty--a randomized controlled trial. Clin Rehabil. 2007; 21(8):719-728. [PubMed: 17846072]

Van Damme S, Gallace A, Spence C, Crombez G, Moseley GL. Does the sight of physical threat induce a tactile processing bias? Modality-specific attentional facilitation induced by viewing threatening pictures. Brain Res. 2009; 1253:100-106. [PubMed: 19094970]

Warber S, Cornelio D, Straughn J, Kile G. Biofield energy healing from the inside. J Altern Complement Med. 2004; 10(6):1107-1113. [PubMed: 15674009]

Wayne PM, Krebs DE, Macklin EA, Schnyer R, Kaptchuk TJ, Parker SW, et al. Acupuncture for upper-extremity rehabilitation in chronic stroke: a randomized sham-controlled study. Arch Phys Med Rehabil. 2005; 86(12):2248-2255. [PubMed: 16344019] 


\section{Table 1}

Patients' descriptions of "enhanced touch sensations" associated with the placebo acupuncture ritual

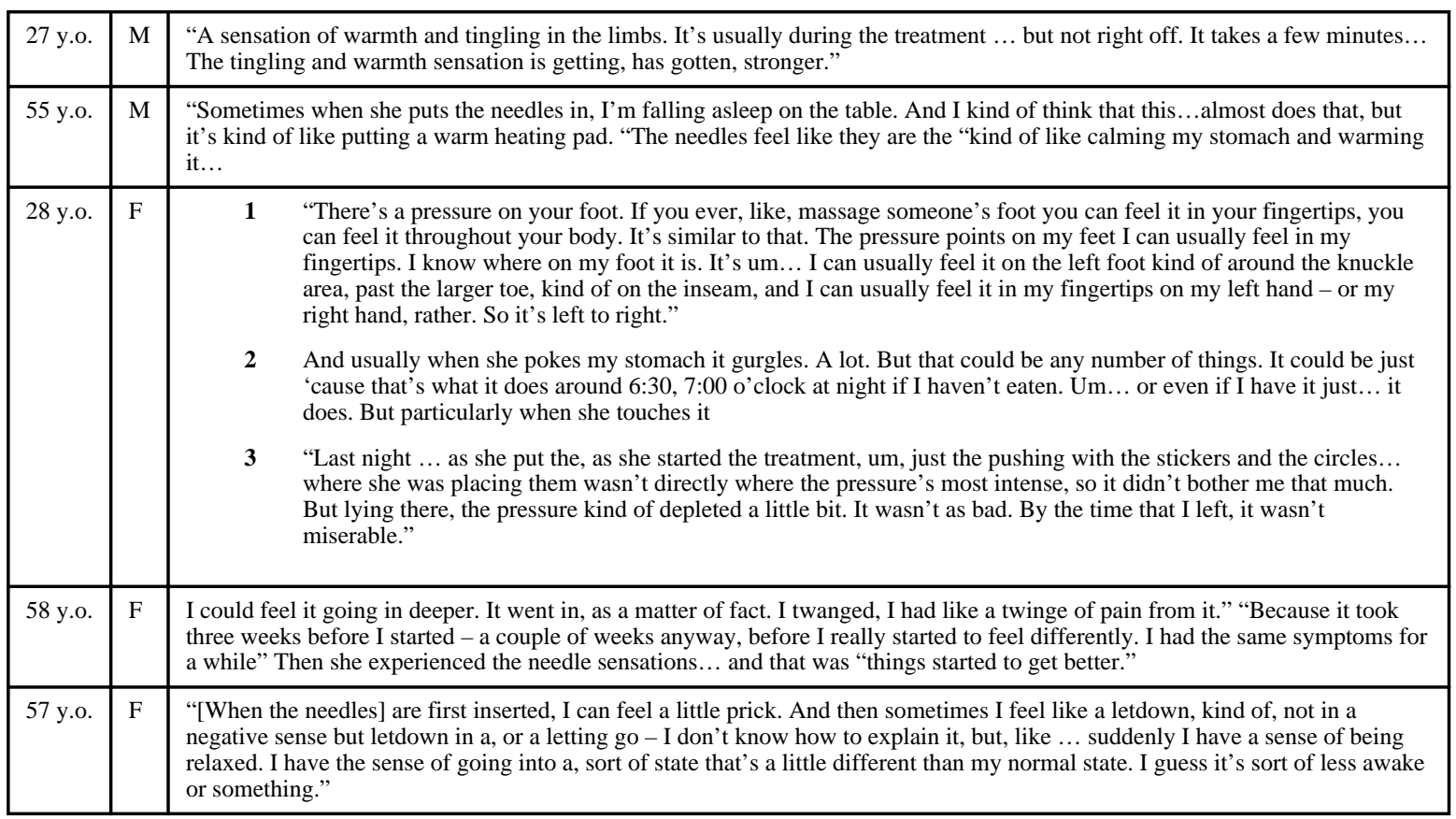

